\title{
Paraseismic effects of the fundamental structure dynamic simulation
}

\author{
Branislav Valent ${ }^{1, *}$, Martin Ščotka ${ }^{2}$ \\ ${ }^{1}$ DOFF s.r.o., Klemensova 16/3,010 01Žilina, Slovakia \\ ${ }^{2}$ University of Zilina, DSMAM, Univerzitna 1, 01026 Žilina, Slovakia
}

\begin{abstract}
The paraseismic effect due to civil structures construction may cause cracks in buildings around the source of the vibration. The vibrations velocities of the source transmitted to the surrounding buildings can be used as excitation to the numerical simulations. In the paper the case study of the assessment of the real civil structure dynamic simulation is presented. The response is evaluated and compared to the critical values in national standards.
\end{abstract}

\section{Introduction}

This aim of the paper is to determine the construction response of ALLIANZ Slovenská poist'ovňa branch in Paulínska Street in Trnava to the technical seismic loading. The technical seismicity in this case was caused by vibrations from sheet pile driving in the vicinity of the Allianz building. During the driving process, an experimental measurement of the Allianz building construction response was carried out by an accredited laboratory of INSET. The response will be evaluated and compared to the critical values in national standards [1]. The results of this measurement showed vibration velocity amplitudes in the reference point of the assessed building close to the standard limit requiring dynamic calculation[2, 3, 4]. However, the standard limits were not exceeded with any measurements. Nevertheless, the investor of the sheet pile shoring implementation had requested this expert opinion, which contains a dynamic calculation of the response to the mentioned dynamic load. The resulting report titled "Semi-empirical Calculation of the construction response due to Technical Seismicity" also includes an assessment of dynamic load effects. This calculation is semiempirical because it is not carried out on a calculation model drawn up by the Allianz building project architect [5].

\section{Dynamic model}

For the purpose of this assessment, the simplified calculation model of the Allianz building was created. On the basis of the documentation (drawings of the reinforced concrete elements) provided by the investor, the reference stiffness values of the rod and slab components were gradually entered and calculated. Detailed parts as simplification of

*Corresponding author: $\underline{\text { scotka1@uniza.sk }}$ 
geometry and omitting some elements (stairs, walls, etc.), working on the safe side, because of considering the dynamic load, were applied and would increase rigidity and structural strength. The basic shape, dimensions and kinematic boundary conditions complied with the calculation model. If the results are satisfactory for the less-favored model, the detailed model (working on the safe side) also matches automatically. The simplified computing model is shown in Figure1.

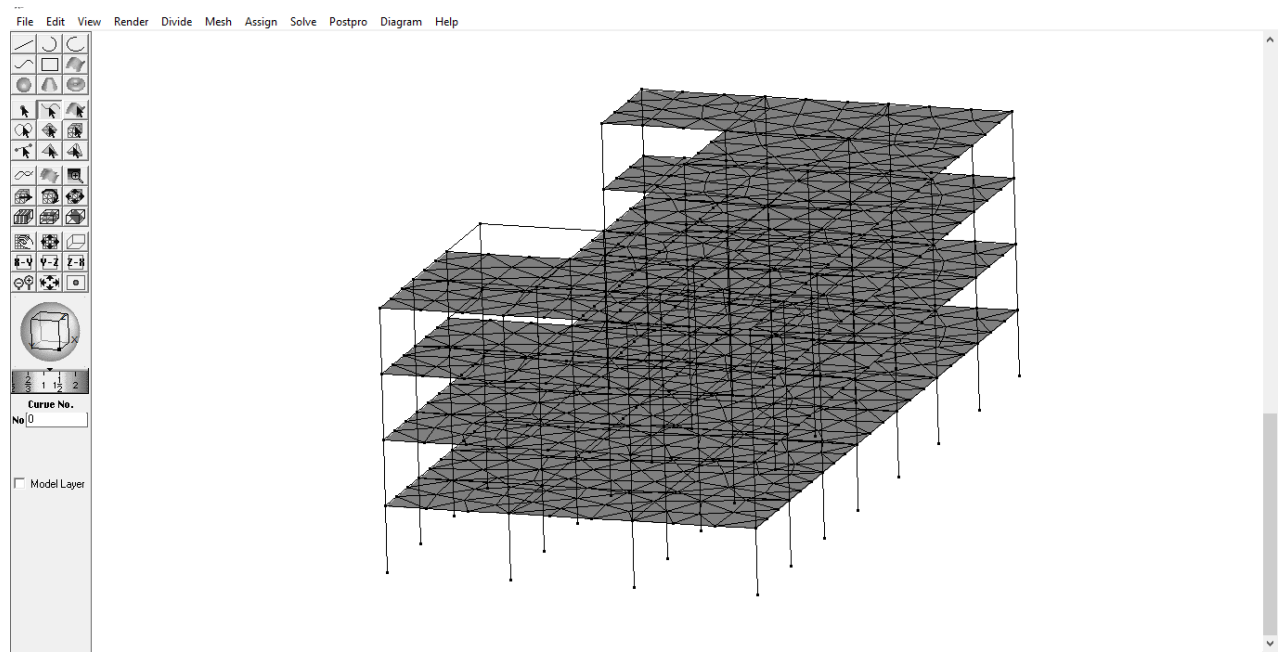

Fig. 1. Computing model

In order to assess the response in the frequency domain for the resonance criterion, two basic vibration mode shapes with a mass-to-shape coefficient greater than 80 percent were solved using the calculation model (Figure 2) with natural frequencies $\mathrm{fl}=1.89 \mathrm{~Hz}$ and $\mathrm{f} 2=1.94$ $\mathrm{Hz}$. These mode shapes are horizontally global (of the entire system) that are relevant for assessing seismic effects.

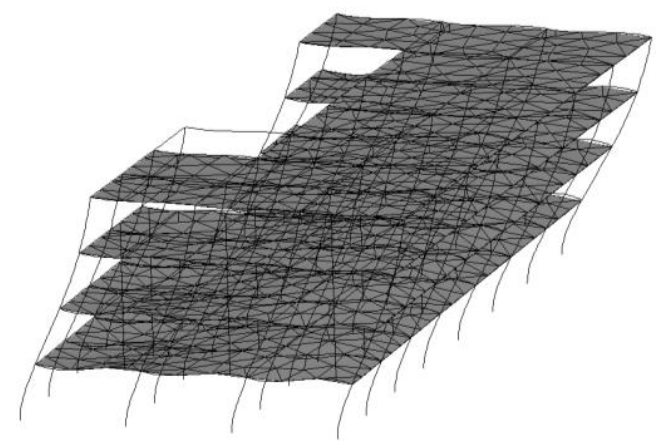

Fig. 2. Global natural eigen shapes

The initial load for the dynamic calculation in the time domain was used from the measurement recorded on the Allianz building reference point in three mutually perpendicular directions $\mathrm{X}, \mathrm{Y}, \mathrm{Z}$ according to the orientation in the calculation model. The 
record was selected as a record with values close to the standard limit for the dynamic calculation purposes (Figure 3). The sampling rate of the measurement was $1000 \mathrm{~Hz}$ and the time step entered into the calculation was $0.001 \mathrm{~s}$. The system recalculates the input for frame footing points through exponential attenuation regression using the Raighley fading parameters for the geological profile environment provided by the investor $\langle=0,15$ and $\AA=$ 0,000015 .

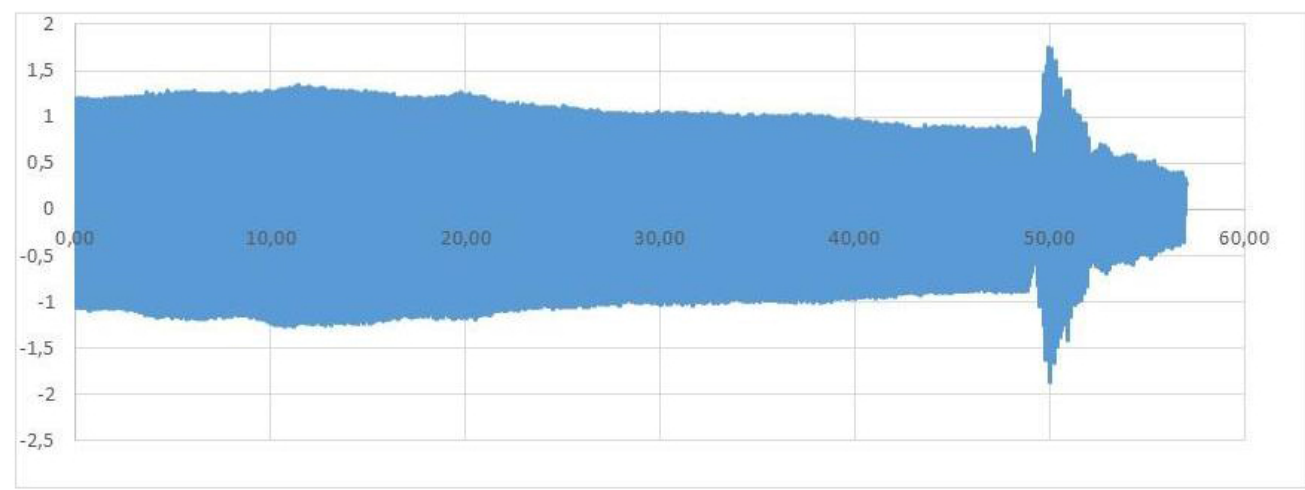

Fig. 3. The dynamic load on the Allianz building

The results in the time domain for the critical increment peaks of cross-section forces are shown in Figure 4.
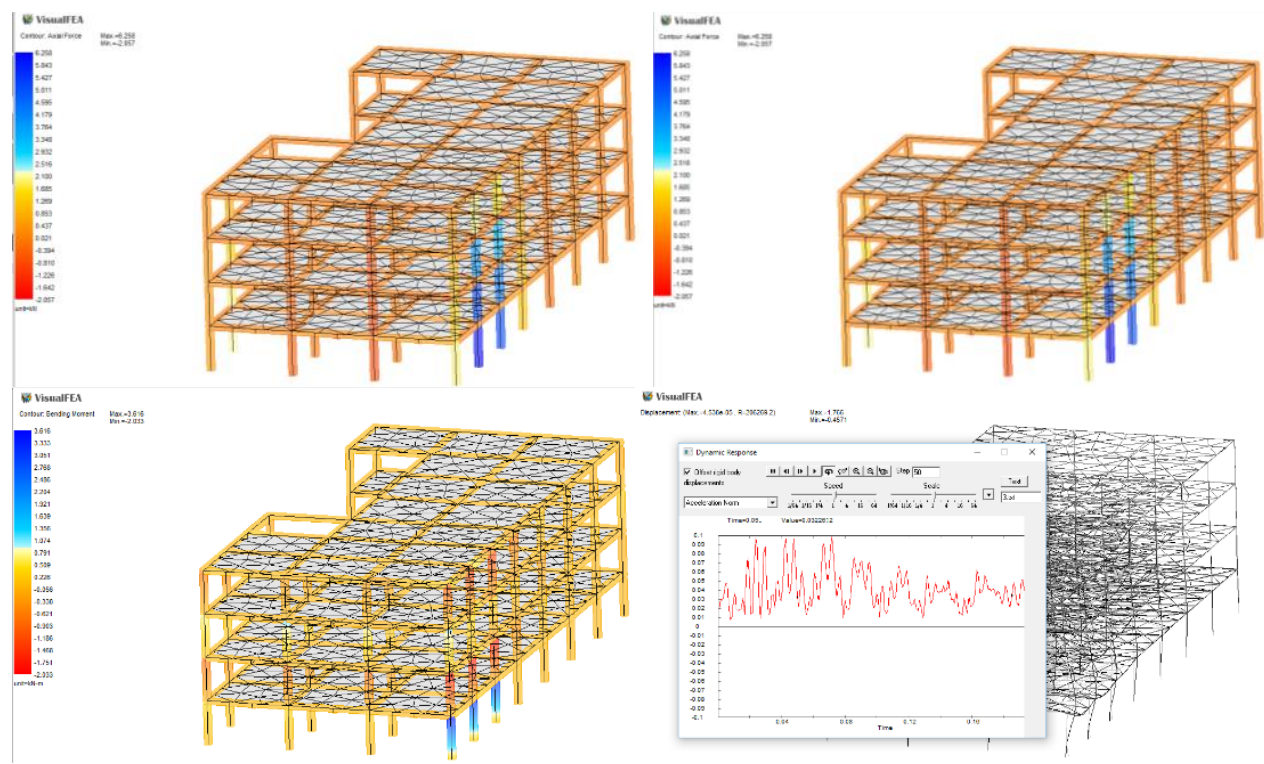

Fig. 4. The dynamic load on the Allianz building 


\section{Conclusion}

The results of the calculation based on the outputs presented in the previous chapters show the following facts for the ALLIANZ Slovenská poist'ovňa building on Paulínská Street in Trnava:

1. The calculation using the simplified model was also performed in the frequency domain for the determination of natural frequencies and eigen shapes as well as for the calculation of the amplitude spectrum of vibration acceleration at the entrance to the building. With respect to the resonance criterion, for the seismic load, the structure in question has the most energetically significant natural frequencies $\mathrm{fl}=1.89 \mathrm{~Hz}$ and $\mathrm{f} 2=1.94 \mathrm{~Hz}$. The most significant frequency band of seismic excitation is higher with its peak approximately $\mathrm{fB}=$ $20 \mathrm{~Hz}$. Therefore, it is obvious that with the standard damping processes of reinforced concrete monolithic structures, resonance will not occur due to the impact of sheet pile driving [6].

2. As for the amplitude analysis the extreme values of parametric quantity increase, especially axial force, shear force and bending moment are the most important for the building. The values are: $\operatorname{Nmax}=6.28 \mathrm{kN} ; \operatorname{Vmax}=2.51 \mathrm{kN} ; \operatorname{Mmax}=3.62 \mathrm{kN}$. These values are in level with the percentage of parametric quantities from the design load combinations for the marginal load factor within the investigated structure. Thus, with a good static design, the building has a sufficient load-bearing capacity, both in partial coefficients but also in the project designer's reserve. However, vibrations in the building can be physically felt because they occur in a sensitive zone for humans and, as the dynamic analysis shows, they also acquire high enough amplitude for their perception [7]. In terms of the building structure, however, they do not cause a risk of damage to the load-bearing system in the time domain.

With technical seismicity, there is always the compaction of the subsoil phenomenon under the building foundations, but there is no criterion for this aspect and such occurrence is a subject of further research. However, for the clay subsoil in this case, this effect is very unlikely.

This paper was created with the support of the OP Education for the project "Quality education support and research for the transport sector as the engine of the economy" (ITMS: 26110230076), which is cofunded by the European Social Fund.

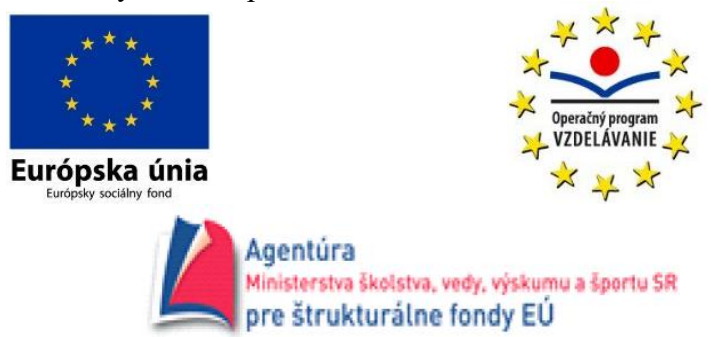

Modern education for knowledge society / The project is co-financed by EU funds.

\section{References}

1. STN EN 1998-1: (2005) „Design of structures for earthquake resistance.“Part 1: General rules, seismic actions and rules for buildings, Bratislava. 
2. D. Papan, Z. Papanova, Numerical models for the elastic halfspace dynamic response due to road traffic load, MATEC WEB OF CONFERENCES, Volume 251, (2018)

3. L. Figuli, Š. Jangl, D. Papán, Modelling and Testing of Blast Effect On the Structures, Published under licence by IOP Publishing Ltd, IOP Conference Series: Earth and Environmental Science, Volume 44, Issue 5, (2016)

4. D. Papán, Z. Papánová, Spectral Analysis of the Structures due to Traffic, Procedia Engineering, Volume 91, Pages 171-176, ISSN 1877-7058, (2014)

5. Allianz Design, Static and architectional drawings, HKM Staving Projekt spol. s.r.o., Banská Bystrica, Slovakia, (1995)

6. D. Papán, Z. Papánová, Higher frequency dynamic response analysis of the foam concrete block element, MATEC Web Conf. 19601037 (2018)

DOI: $10.1051 /$ matecconf $/ 201819601037$

7. D. Papan, K. Demeterova, The Dynamic FEM Models Results Comparison of the New Bridge Over Danube River in Bratislava, PROCEDIA ENGINEERING, Volume 161,Page 1300-1307, (2016) 